\title{
Forming the initial European Statements of Hospital Pharmacy
}

\author{
Aida Batista, ${ }^{1}$ David Preece ${ }^{2}$
}

'Department of Pharmacy, Centro Hospitalar de Vila Nova de Gaia/Espinho, EPE, Vila Nova de Gaia, Portugal ${ }^{2}$ Department of Policy and Advocacy, The European Association of Hospital Pharmacists, Brussels, Belgium

\section{Correspondence to}

Dr Aida Batista, Department of Pharmacy, Centro Hospitalar de Vila Nova de Gaia/Espinho,

EPE, Rua Conceição Fernandes, Vila Nova de Gaia 4434-502, Portugal; aida.batista@apfh.pt

Received 25 July 2014 Revised 30 July 2014 Accepted 31 July 2014

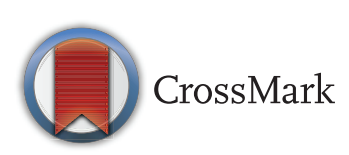

To cite: Batista $A$ Preece D. Eur J Hosp Pharm 2014;21:259-261.

\section{INTRODUCTION}

In anticipation of the European Summit on Hospital Pharmacy preliminary work was required. This article intends to describe the whole process of choosing the basis of the work, the discussions and construction of statements that would be introduced to the Delphi process with the objective of determining which statements would be voted on at the Summit by hospital pharmacists, patient representatives and healthcare professionals.

\section{MISSION AND GOALS OF WORKING GROUP 2}

For the task of preparing a version of statements that would be subject to the Delphi process, intended to be one of the building stages of European statements, it was decided to create a working group, which was called the Working Group 2 (WG2), assisting the other groups to prepare the Summit.

The mission of WG2 was to review the International Pharmaceutical Federation (FIP)'s 2008 Basel Statements of Hospital Pharmacy Practice $^{1}$ with a view to their applicability in the European context.

The Basel Statements would have to be identified and revised according to their relevance and meaning for the future of European hospital pharmacists and also according to their importance and impact on patient outcomes. In the translation of the meaning of statements, the group should always bear in mind the following questions:

- What hospital pharmacists do

- Why they do it

- Who they do it with (patients, doctors, nurses)

- How they will do it.

The expected result of the work and consequently of the Summit itself would be a pathway to achieve the best possible practice in Europe, always seeking the best outcomes and improved patient safety. As a result, it was intended to increase and improve the trust among hospital pharmacists, patients and all stakeholders.

\section{FIRST OPERATIONS}

The work began at a meeting of a small group invited by the Board of the European Association of Hospital Pharmacists (EAHP) and held in September 2012.

During the meeting it was established, among other things, how to begin the task of selection and construction of the European statements.

After some discussion it was agreed that the starting point would be to work with the Basel Statements. The reason for the choice was pragmatic. The Basel Statements were approved in 2008 in Basel, Switzerland at The Global
Conference on the Future of Hospital Pharmacy, during the 68th Annual Congress of the International Pharmaceutical Federation (FIP), which was organised by the Hospital Pharmacy Section of FIP. The statements were scrutinised by 348 pharmacists from 98 countries and can be considered as a basic consensus document reflecting the vision of the pharmaceutical profession developed in hospitals. With this assumption and acceptance of the robustness of the Basel Statements, it was decided that based on principles that are applied globally, EAHP could build standards of activity focused on the European reality.

The milestone that was the approval and publication of the Basel Statements was at that time considered of great importance for hospital pharmacists around the world and therefore the document could be considered as the starting point for any future work. Two points were also mentioned: first, some of the principles expressed do not adapt to the reality of European hospital pharmacy practice; and second, although the Basel Statements do translate what hospital pharmacists do, to some extent, they lack how to get there in practice. One of the goals of the Summit, in addition to the presentation of the European Statements of Hospital Pharmacy, is to indicate a way for European hospital pharmacists to achieve both levels of common practice and best practice.

\section{WG2'S CONSTRUCTION}

This group needed experienced professionals with useful and pragmatic thoughts to help us understand what might be possible in terms of adapting the FIP document to recreate the statements in a way appropriate for European hospital pharmacy practice.

The group included members who had participated in the drafting and voting process of the Basel Statements; representatives from the members of EAHP, ideally delegates to the EAHP General Assembly; this was vital due to the geographical and regional differences within Europe. Obviously members of the hospital section of FIP were invited, since the Basel Statements were produced by this organisation. Finally, it included members from the EAHP Board and designated individuals from the EAHP office for all the support needed to gather the contributions and to ensure the use of appropriate English.

The final group was composed of:

- Aida Batista, EAHP Board Member (Working Group leader), Portugal;

- Roberto Frontini, EAHP President, Germany;

- Richard Price, Policy and Advocacy Officer, EAHP; 
- David Preece, Research Assistant, EAHP;

- Ana Crnkovic, Hospital Pharmacist, Croatia;

- Brigitte Waldispuehl, Hospital Pharmacist, Switzerland;

- Elaine Conyard, Hospital Pharmacist, Ireland;

- Francesca Venturini, EAHP Board Member, Italy;

- Helena Farinha, Hospital Pharmacist, Portugal;

- Jacqueline Surugue, President of FIP Hospital Pharmacy section, France;

- Joan Peppard, EAHP Board Member, Ireland;

- Leonidas Tzimis, Hospital Pharmacist, Greece;

- Marika Saar, Hospital Pharmacist, Estonia;

- Robert Moss, Vice-President of FIP Hospital Pharmacy section (Europe), Netherlands;

- Valdis Pirsko, Hospital Pharmacist, Latvia.

\section{CHALLENGES}

WG2 faced several challenges, but those that had greater significance were the following.

\section{The variability of practice}

A reinterpretation of the Basel Statements was conducted to investigate understanding of the meaning of the statements by hospital pharmacists, and also patients, health professionals and the general public. There are some differences in hospital pharmacy within Europe, which can be among hospitals in the same country or from different countries. It was necessary to take into account this variability to achieve statements applicable to all, or at least to the majority of hospital pharmacies.

\section{Defining the target audience}

The statements needed to be constructed as a tool for hospital pharmacists to be used in their daily practice, in the dissemination and understanding of its activities relating to patients, healthcare professionals and the public, but also as a document used for political purposes at the national and European level.

\section{The language barrier}

Although the official language was English, interpretations are not always the same, so the wording used needed to be very carefully selected.

\section{WG2'S METHOD AND DELIBERATIONS}

In the first phase, the group selected from among the 75 Basel Statements those that were considered the most important for hospital pharmacists based in the following areas of activity: procurement and distribution; production and compounding; clinical services; quality assurance and patient safety; education and research. A section was also created to encompass the statements considered to be introductory and governance. The group was asked to rank all the statements according to the impact on patients (direct or indirect impact) and also according to the relevance to hospital pharmacy practice in Europe (very important; important; not so important).

The statements were classified and suggestions and comments were taken on whether to delete statements, to merge some of them into one, or to introduce new statements.

After selecting the basic statements, the group rewrote them considering the following rules: the 'new' statements should be patient oriented, specific, measurable, achievable, realistic and time scaled; they should give all European pharmacists a vision of how to move on towards the best possible practice and excellence; whenever necessary they should give a pathway to achieve the goal (from basic to excellent); and they should be simple, short and clear.
As already mentioned, it would be the first time that statements on professional activity would be scrutinised not only by hospital pharmacists (the same profession) but also by patients and other healthcare professionals. With this in mind, the group also tried to make interpretations/explanations of the language used by hospital pharmacists in a way to be understood by other groups who would vote at the summit.

Most of the work was done with the exchange of messages via email with two face-to-face meetings. The work began in January 2013 and ended in October 2013.

\section{KEY OUTCOMES}

The review of the Basel Statements highlighted some of the areas of hospital pharmacy practice that were conducted differently in Europe. This was clear from the initial discussions in the Working Group and are summarised by the following discussions.

\section{Introductory statements and governance}

The overarching statements reviewed highlighted the most important aspects of European hospital pharmacy practice and included the governance requirements expected from hospital pharmacy departments.

\section{Selection, procurement and distribution}

The original statements included the themes of transparency and accountability, together with operational flexibility. These themes (in statements 17 and 20) were considered important and also of a suitable nature to be merged. Likewise statements on purchasing for safety and quality assurance (contained in statements 18 and 21) were also discussed and the possibility of merging considered.

\section{Production and compounding}

Since the Basel Statements (2008), the European Directorate of Quality Medicines (EDQM) published a European Council resolution on production in 2011 . $^{2}$ WG2 felt that it was important to contain within the EAHP statements aspects of this resolution as an update in hospital pharmacy practice.

In addition, it was noted that statement 52 restricted the patient population who may require compounded medicines to the paediatric and neonatal population.

\section{Clinical services}

The input of the pharmacist, sitting on the Drug and Therapeutics Committee was considered a very important point, and this statement was strengthened (statement 27). A formulary was commonly used within Europe and it was decided to move this statement (26) to the procurement section.

The access of the pharmacist to the patient care record was a hotly debated topic. It was agreed that pharmacists require the information to make informed recommendations, but the debate about the level of access and also the requirements for document interventions were taken forward to the Delphi Process.

Regarding the practice of hospital pharmacy (monitoring the patient's medicine) and the difference in practice in the situation of recourse limitations (statement 11), it was considered that resource limitation required a new, separate statement. Members of WG2 provided examples of restrictions that did not allow them to provide the very best care to their patients and this had altered how the hospital pharmacy operated. 


\section{Patient safety and quality assurance}

A new statement was proposed regarding medication errors (strengthening statement 38). Additionally merging of statements 34 and 44 regarding labelling/storage and labelling prior to administration was proposed. Quality assurance regarding the administration of medication (statements 55 and 56) was considered important; nevertheless it was proposed to merge these statements.

The role of the hospital pharmacist in the responsibility for the logistics and storage of medicines was highlighted in separate statements (8 and 39). A statement containing both aspects was proposed.

Statement 47 highlighted the requirement for trained personnel to handle hazardous medicines. This was moved and reformulated from the education and research section.

\section{Education and research}

Aspects of the previous section, human resources and training, were utilised in this section, which described the role of pharmacist competences, education requirement and involvement in research activities, including clinical trials and pharmacy practice research (table 1 ).

The outcomes of WG $2^{3}$ were sent to EAHP members (and invited observer organisations) for an initial consultation. ${ }^{4}$ This consultation was conducted to evaluate the statements produced by WG2 and allow input from invited observer organisations.

Following this initial consultation, recommendations were proposed by EAHP member organisations.

\section{Introductory statements and governance}

EAHP Statement 7-'responsible use of medicines' was proposed to substitute 'rational use of medicines'.

\section{Selection, procurement and distribution}

EAHP Statement 11-'This must be a transparent process and any conflicts of interest should be disclosed' was added to strengthen this statement.

EAHP Statement 13-regarding logistics in the hospital, it was clarified that the responsibility of the hospital pharmacist was 'either direct(ly) or by educating others'.

EAHP Statement 14-the use of the patient's own medicine and the process of medicine reconciliation should be registered on the medical record, with the addition that this was 'confirmed by the hospital pharmacist'.

EAHP Statement 15-the preparation of a medicine not commercially available was strengthened by also 'consider(ing) the need for supply after discharge'.

\section{Clinical services}

EAHP Statement 28-seamless care was highlighted between transfer of healthcare settings, with the inclusion of 'in or outside the hospital'.

\section{Education and research}

EAHP Statement 44-the role of CPD was encouraged, as part of assessing the competence of the hospital pharmacist.
Table 1 Classification and number of statements in each section resulting from the work of Working Group 2 compared with the original Basel Statements

\begin{tabular}{|c|c|c|c|}
\hline \multicolumn{2}{|l|}{ Basel Statements } & \multicolumn{2}{|l|}{ Reviewed EAHP Statements } \\
\hline Overarching statements & 16 & $\begin{array}{l}\text { Introductory statements and } \\
\text { governance }\end{array}$ & 7 \\
\hline Medicines procurement & 9 & $\begin{array}{l}\text { Selection, procurement and } \\
\text { distribution }\end{array}$ & 7 \\
\hline Influences on prescribing & 7 & Production and compounding & 8 \\
\hline $\begin{array}{l}\text { Preparation and delivery of } \\
\text { medicines }\end{array}$ & 9 & Clinical services & 7 \\
\hline Administration of medicines & 16 & $\begin{array}{l}\text { Quality assurance and patient } \\
\text { safety }\end{array}$ & 11 \\
\hline $\begin{array}{l}\text { Monitoring of medication } \\
\text { practice }\end{array}$ & 8 & Education and research & 8 \\
\hline Human resources and training & 10 & & \\
\hline Total & 75 & Total & 48 \\
\hline
\end{tabular}

In summary, the statements received minor additions during this consultation, as they received high levels of agreement from EAHP members. They were then submitted to the Delphi Process for further review with external moderators, input from patient representatives and other healthcare professionals.

\section{REFLECTIONS}

It was very rewarding to be part of a group whose work was essential in the outcome of the European Summit on Hospital Pharmacy. European hospital pharmacists from 13 countries worked together, trying to identify common themes and differences, and were able to build a document that has subsequently been modified and improved by two rounds of the Delphi process. The outcome of the work of WG2 and the Delphi process was finally voted on at the European Summit on Hospital Pharmacy held on 14 and 15 May 2014 in Brussels, Belgium and used as a foundation for EAHP practice development activity in the future.

Competing interests None.

Provenance and peer review Commissioned; internally peer reviewed.

\section{REFERENCES}

1 FIP Global Conference on the Future of Hospital Pharmacy-Final Basel Statements. 2008 (cited 1 April 2014). https://www.fip.org/files/fip/HPS/Basel2008/

FinalBaselStatements.pdf

2 Council of Europe-Resolution CM/ResAP(2011)1 on quality and safety assurance requirements for medicinal products prepared in pharmacies for the special needs of patients. 2011.

3 EAHP Statements on Hospital Pharmacy 2014-initial consultation version October 2013. 2013 (cited 25 July 2014). http://www.eahp.eu/sites/default/files/files/EAHP\% 20Statements\%20on\%20Hospital\%20Pharmacy\%202014-\%20Initial\% 20consultation\%200ctober\%202013.pdf

4 EAHP. The European Summit on Hospital Pharmacy - a guide to the consultation process. 2013 (cited 25 July 2014). http://www.eahp.eu/sites/default/files/files/Guide $\% 20$ to $\% 20$ the $\% 20$ Summit $\% 20$ consultation\%20process.pdf 